\title{
Limitations and possibilities on health assessment to women in violence situation
}

\author{
Laura Ferreira Cortes ${ }^{1 *}$, Stela Maris de Mello Padoin ${ }^{1}$, Cristiane Cardoso de Paula ${ }^{1}$, \\ Letícia Becker Vieira ${ }^{2}$, Maria Celeste Landerdahl ${ }^{3}$, Ethel Bastos da Silva ${ }^{3}$ \\ ${ }^{1}$ Nursing Graduate Department, Federal University of Santa Maria, Rio Grande do Sul, Brazil; \\ *Corresponding Author: lferreiracortes@gmail.com \\ ${ }^{2}$ Nursing Graduate Department, Anna Nery School of Nursing, Federal University of Rio de Janeiro, Rio de Janeiro, Brazil \\ ${ }^{3}$ Nursing Department, Federal University of Santa Maria, Rio Grande do Sul, Brazil
}

Received 24 April 2013; accepted 26 May 2013; accepted 15 June 2013

Copyright (C) 2013 Laura Ferreira Cortes et al. This is an open access article distributed under the Creative Commons Attribution License, which permits unrestricted use, distribution, and reproduction in any medium, provided the original work is properly cited.

\section{ABSTRACT}

The aim was to know how health assessment to women in violence situation is developed. Literature review on LILACS and MEDLINE databases was conducted in April 2013 with the descriptors: "domestic violence" and "women's health", on a 1994-2012 timeframe. Statistics characterization and content theme analysis of the scientific production were developed. Results showed that the assessment is permeated by institutional limitation and an approach strictly clinical that makes identification and diagnosis of violence difficult, reinforcing invisibility in health care. Professional assessment is influenced by socio-cultural and the naturalization of the phenomena, which is not considered a public health issue. Technical knowledge is insufficient, making the possibility of promoting violence cycle rupture difficult. However, we envisage reception as a possibility to assess female demands. We conclude the need to include the theme in health undergraduate courses and also the urgency of this learning experience to support a multidisciplinary and intersectoral work web. Thus, rethinking assessment as a way of (re)organizing how health care is structured in order to compose an assessment web to women and guarantee reception of their demands is needed. Else, constructing competence allied to coping public policy to the problem and guaranteeing a human and full assistance will stay only on the academic field, constituting itself as a limit on protecting life of these women and their families.

Keywords: Women's Health; Violence against
Women; Health Services; Delivery of Health Care

\section{INTRODUCTION}

Violence against women has emerged an important determinant of women's health, as well as a serious public health problem because of the magnitude of epidemiological data, spending on health care, social, economic, in the lives of women and others involved [1]. It is defined as any action or omission based on gender which they cause death, injury, psychological distress, sexual or psychological and moral damage or equity in both the public and private [2-5].

While men tend to suffer violence, in general, are practiced in a public space, women, in general, suffer daily with a phenomenon that manifests itself in their own homes and, the majority of times it is practiced by partners and family members. It is comprehended as a powerful instrument, resulting of genre, social class, race, ethnicity and generation inequalities [3,6]. It is a violation to human rights, to life and to health, involving multiple social segments.

It is recommended that interventions aimed at women in situations of violence are through a network of skilled care, and articulate representative of the singularities of women seen coupled with social support $[7,8]$. However, it is in the health field, displaying their consequences [9]. Thus, the health sector has been pioneering and strategic identification of violence and production critical and reflective about this phenomenon [10].

Despite its importance which is that the attention these women have been piecemeal and ad hoc restricted to treatment of physical injuries, demonstrating unpreparedness of services to develop a service network, resolute and seeking completeness [11,12], it is disjointed when they have to go through many paths in services [8], 
which can be linked to the fact that violence is still not regarded as a cause in demand for services, and is considered often as a matter of the private and not public health [12].

In this perspective, it is important to know what is being done in the health of women in situations of violence. Therefore, the question is: how health care of women in situations of violence is developed? Thus this study aimed to identify, through the scientific literature, the developed health care of these women.

\section{METHOD}

Literature review guided the steps: preparing the goal of the research question and the criteria for inclusion and exclusion, selection of studies, data extraction, analysis and discussion of the results [13]. The search was developed in the Virtual Health Library (BIREME), the electronic database Latin American and Caribbean Health Sciences (LILACS) and the Online System Search and Analysis of Medical Literature (Medical Literature Analysis and Retrieval System onlineMEDLINE).

The search occurred in April 2013. Descriptors: "domestic violence" and "women's health". The temporal delimitation was from 1994 to 2012, having as a landmark American Convention to Prevent, Punish and Eradicate Violence against Women [4]. The search strategy of the production was: ("domestic violence") and "women's health" [Subject descriptor] and "year of publication" and "SPANISH" or "ENGLISH" or "PORTUGUESE" [Language]. This resulted in 104 productions in the database LILACS and MEDLINE 313, totaling to 417 publications.

Inclusion criteria: research article to be written in Portuguese or Spanish or English, and meet the research objective. Exclusion criteria: not have abstract or summary incomplete availability of full text online. Productions were excluded from previous reading of titles and abstracts (Figure 1). To access full text, we used the following resources: available link, directly from the database LILACS and MEDLINE, search on journal directory that the article was published, search on CAPES (Coordination of Improvement of Higher Education Personnel) directory and search on Google.

Articles characterization was presented as absolute and relative frequency, through documentary record consists of variables. For analysis of the items was used to record data extraction variables: objective, year, origin, periodical publishing, area of knowledge, methodological approach (quantitative and qualitative), subject, setting, results and main contributions converged with research question of the study.

We used the thematic content analysis [14], which has three stages: pre-analysis, material exploration and inter-

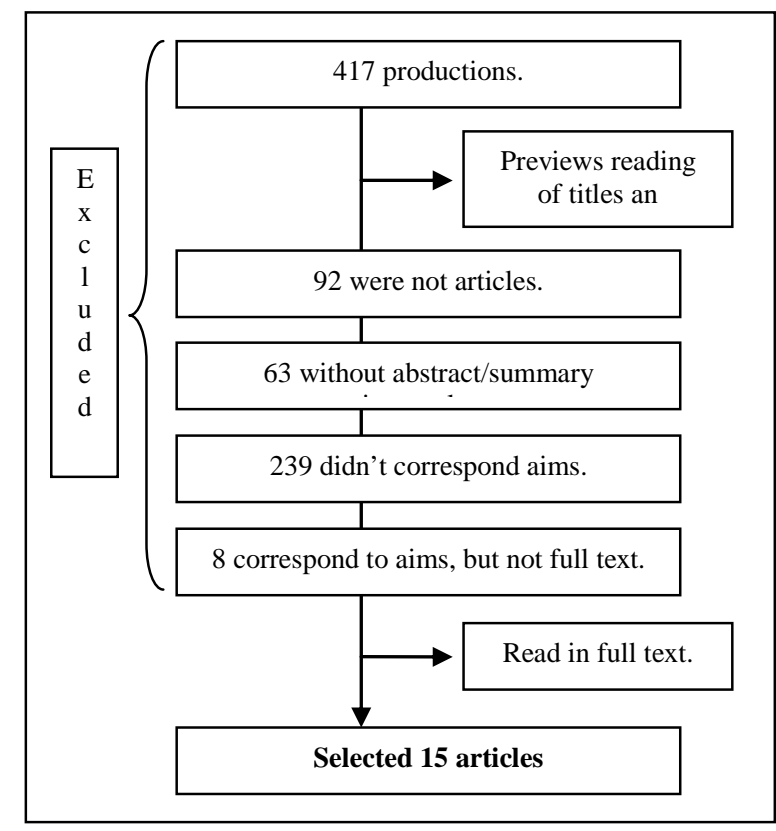

Figure 1. Diagram of screening process of the literatures.

pretation of results. We conducted initial reading and record keeping (documental form and form data extraction), providing a comprehensive view of the content. A full reading of the article allowed the transcription of results and significant stretches. A thorough reading was given by rereading texts when coding was developed from the findings. The thematic categories, elaborated with references of the authors and synthetic analysis of texts, allowed better visualization, allowing relationships and syntheses in the search for convergence, divergence and similarities from the viewpoint of different authors in the interpretation of results.

\section{RESULTS}

As for the origin of studies, we verified $53.3 \%$ of productions are from Brazil, of these, one was published in international scale, followed by United States of America (20\%). As for the study approach, $60 \%$ of productions were qualitative. According to year of publication, 26.6\% were 2005, 2004 (20.0\%), 2006 and 2007 (13.3\%), 2002, 2003, 2008 and 2012 (6.6\%). Mainly prevalent studies in health care units (46.0\%), followed by intersectoral units (20.0\%). Productions were collaborated by multi-professional team (40.0\%); nursing (26.6\%); medicine (6.6\%); law (6.6\%), social services (6.6\%) and politics science (6.6\%) (Table 1).

Content analysis resulted in two empirical categories [14]: The health care of women in situations of violence is permeated by institutional constraints and approach; Attention to women in situations of violence permeated the host enables women to meet the demands. 
Table 1. Characterization of Productions.

\begin{tabular}{ccc}
\hline Origin & N & $\%$ \\
\hline Brazil & 8 & 53.3 \\
United States & 3 & 20.0 \\
United Kingdom & 1 & 6.6 \\
Mexico & 1 & 6.6 \\
Costa Rica & 1 & 6.6 \\
South Africa & 1 & 6.6 \\
Scenery & & \\
Health care units & 7 & 46.0 \\
Intersectoral health care units & 3 & 20.0 \\
Cop services & 1 & 6.6 \\
Non-governmental organization & 1 & 6.6 \\
University & 1 & 6.6 \\
Not Informed & 2 & 13.3 \\
\hline
\end{tabular}

\subsection{Assessment to Women in Violence Situation is Permeated by Legal, Institutional, Approach and Conception Limitations}

Institutional constraints refer to the organization of services, the lack of tools that guide the identification and registration of cases [15-18]. What resonates in the absence of statistics to gauge the incidence of violence against women [17].

There is sufficient supply of services [18-20] and no shortage of places that guarantee privacy in care $[21,22]$. Although health services are the most sought after by women are the least refer to the continuity of care [16, $17,22,23]$. There is a lack of professional support services for women to deal with violence and his own role in the health care network, and the importance of the joint [24]. Due to transport costs, changes and exchanges of professional women have difficulty accessing services [24,25].

Limitations of approach refer to clinical emphasis [16-18,22,26,27] and the limited understanding of the professionals on violence against women. The emphasis is given to clinical negligence and lack of sensitivity of some professionals [25] to accommodate these women, which hampers communication between professionals and users [17]. These services by accessing the indirect causes, or injuries, headache, mental health problems such as depression, among others $[16,20]$. In general, the professional can not establish a diagnosis compatible with the problem presented by women, not identifying the lesions as violence $[16,22]$. There are difficulties of health professionals in addressing and subjectivity that is converging with the needs of users $[20,25]$.

Care practices are negatively influenced by the limited understanding of the professionals on violence, which is rooted in conceptions of gender $[16,18,28]$, adding postures as judgment and blaming the violence suffered by women $[16,18,25,26,28]$; stigma, prejudice, discrimination and the idea that violence against women is an act which by itself justified [18,20,28].

Added to the limitations of the naturalisation act of aggression as a need to discipline women, regarding the rape, some professional men consider only when the act is done by strangers, so the notion of spousal abuse is not accepted [16,28].

Violence against women is understood by professionals as the private sphere $[16,17,26]$, this reinforces the invisibility of violence, which is observed by professionals in health services $[16,17,20,22]$ and by the very women $[17,22,23]$. Overcoming violence implies a revision of values, beliefs and attitudes established [17], since it is naturalized and normalized [28] socially.

Most studies concerning the health professionals have difficulties to address, identify and/or perform the screening of cases of violence against women. Feel overwhelmed [16,17,21,23,26,27], uncomfortable or awkward to deal with a painful situation [16,17,20-23], with a lack of theoretical knowledge and exempt from this responsibility $[16,20,18]$.

Notes to the lack of professional training, a fact that complicates the recognition of cases, the realization of guidelines on the rights of women, effective interventions such as referral and follow-up support services, which may put women at risk [15-17,21,23,25,27]. Many suffer doubly suffering violence by the perpetrator and also by healthcare [28].

These limitations contribute to that there is full recognition of violence as a public health problem [15-17,19, 27]. In general, the interventions are part of the context of public security, social welfare and psychology $[15,17$, 19]. Some professionals understand violence as a matter of law area [18].

\subsection{Assessment to Women in Violence Situation Permeated by Reception Enables to Assist Women's Demands}

The success story of women in situations of violence in services requires institutions to act as support and facilitation instruments in the process of overcoming the violence experienced by them. Thus, the more effective service proved to be free from rigid interventions. The host said through flexibility allows individual situations are considered women's expectations and their needs [18]. 
With regard to the types of services that meet women in situations of violence no specific service has been uniformly identified as effective or not. So, what determines whether the service is appropriate or not to the demands of women are attention life experiences, personal preferences and interpersonal [25]. Even because the trajectories them in their attempts to get rid of violence consist of complex and ambivalent. Therefore it requires the understanding and willingness of professionals and services [18]. It is noteworthy that women do not want that professionals tell them what to do or what is best for them. Blaming, judging their ideas, or stigmatizing them does not help. Be answered by professional women is the preference of the users [16,25].

Was considered positive for them the work of support groups, shelters, welfare units and connecting station listens to 24 hours [20,29]. The community-based services are useful, as well as Alcoholics Anonymous meetings, since many of them develop some kind of psychoactive substances as a result of the violence suffered. For women, the results in their care can improve not by an increase in the provision of services, but from changes in activity and interaction among professionals with careful with them [25].

Highlights the role of activist movements fighting for the rights of women and survivors of domestic violence and intervene in the organization of services. Although few services and professionals who seek the empowerment of these women. It is believed that their participation in decisions about services and policies on the subject can be an important process to stand out [20].

\section{DISCUSSION}

The limitations in the organization of services negatively affect women's health care, since these are at the mercy of the availability of professional staff. The lack of specific flows forces women to wait for the setting up appointments, which can discourage them. It is possible to develop an assistance without burocrazy without using chips of follow ups, reference and conrrefence, and getting back to the women's needs. However, it is necessary to rethink the use of generalizing protocols that gragment assistance with the tendency to pathologize and medicalize the body, which can lead women to go through many services [31,32].

The lack of spaces reserved for the host, which implies the lack of privacy and impersonality, seeming to imply that the health service is not a place to address these demands. The host requires accessibility conditions, privacy and professional empathic listening. It is understandable that attention can be restricted to compliance routines and procedures [30,32]. It is proposed to teamwork, identification of cases in the services, from register proposals and the drive of the intersectoral network system, in order to ensure non-judgment and respect the decisions of women. Listening needs to product a narrative that enables to identify elements with potential to transform the violence situation [32]. It starts with the premise that to meet these women is necessary to develop the bond and trust, which refers to feel secure against those who care, since by itself the context of violence fosters insecurity.

As professionals establish a trusting relationship with women their perception about the support and care received turns, and it is possible to create a stronger connection with the service and initiate a process to leave the violent situation [33]. Women change the use of the health service after their calls with listening skills, reducing their demands for emergency care and turning over the care modalities scheduled [32].

It is observed that in health services whose practitioners are prepared to meet cases of violence against women, they are accepted, they receive information and the right to complaint and networks of support that can be triggered. The professionals involved in cases scoring return to the clinic where she will be monitored. Extend these services to family members in order to include them in the social support network for women. Teams seek to work with the emotional issues of support and occupational psychologist with support from social assistance, seeking to build with women alternatives out of the situation [34]. Techniques that produce specific conversational guidance, mapping the problem and solution alternatives with women are ways to deal with the violence that does not configure a single form for all cases. The evaluation, following this path, you need to verify the impact of the activity on the work of professional and life projects of women seen [32].

The approach to women in situations of violence is essentially clinical and sometimes women avoid to inform professionals about the violence. There justifications ruled in great demand and limited number of professionals who require the service fast and focusing on the symptoms [6]. In general, situations of violence are not considered an emergency, unless the injury caused entail risk of death or sequelae unwanted pregnancy [30].

The inefficient use of health services due to the reduction of the problem to its manifestations in the body understood in biomedical perspective, and the resulting invisibility of violence situations. Process designed as medicalization which reduces the pathologies which are also social problems [32]. The need to approach the professionals beyond the biological approach is identified by the women themselves feel when they demonstrate lack of which showed that the doctors themselves are not only interested in their bodies. They also need information on 
other services available such as counseling [35]. Although this model is dominant biomedical health, there are also centered practices in hospitality, dialogue and the bond as a guide, as initiatives that leverage assistance [31]. Emphasizes that it is important to consider that these women have a higher risk of clinical pathologies and mental, which should be investigated with caution, as part of comprehensive care to be dispensed at the same time they are advised and accepted in their situations of violence [32].

Professionals justify non-involvement by lack of services for effective interventions on the complexity of the phenomenon [6]. In this sense, the support of women is rooted in social assistance, represented by the social worker and the role of Non Governmental Organizations, NGOs, which reinforces the exclusion of the subject of the health [12]. Therefore, women faced in services with a set of practices and feelings that may result in silence, either by shame, fault or often feel responsible for the attack. [12] However, despite the limitations professionals have a unique position to identify cases of violence and make appropriate referrals in situations of violence. Must pay the team a call on the continued health unit and try to overcome the limits as inefficient care network [34].

Furthermore, the limited understanding of the professionals on violence against women committed to service, since it is determined by cultural values and traditional gender stereotypes. The roots of this understanding are grounded in the historical and social identity of men and women who solidifies the power relations between them. In these relationships, the men's delegated power, both in public and in the home. Women it is the condition of subjection to man of breeding, caring for and primarily responsible for the education of children, and these roles naturalized and reproduced. When use of violent men reaffirm the dominance of the female body and the oppression of women, as phenomena that were seen as natural attitudes in social relations and can only be resolved in the private sphere [6,11,36,37].

Thus, violence against women is a form of control and exercise of male power over women. Moreover, the nature of the problem located within the private life and family relationships is difficult to talk and discuss the matter, being naturalized and therefore not being seen as a health problem, not the women themselves, or by professionals. This Fact complicates an attitude of resistance and rupture with the situation experienced.

From the perspective of professional nurses, violence can be a public problem (social), which involves education, family, laws and social assistance. It is still perceived as a problem or the police [12]. To broaden the understanding of professionals is necessary that policymakers provide subsidies to services to identify violence and treat it as a bill of social nature that produces numerous consequences [30].

The unpreparedness of the theoretical and technical professionals allied to the sense of insecurity for working with the theme converges with study in which health professionals had difficulties relating to the identification, care and referral of these women, reinforcing the idea that professionals do not feel qualified to deal with this problem [6]. This context that causes feelings of frustration and helplessness [30].

The recognition of the need for specific training that enables the understanding of gender relations and aspects of human subjectivity, so that its intervention contemplates the women as a whole, enhancing their physical, psychological and social, has emerged as a result of research conducted with Professional [6,30].

To that violence is identified and actions are developed by health professionals are still needed, in most countries, investments to create an institutional culture of exploitation so that professionals may face situations of violence. This requires an agenda beyond the care, accountability and institutional commitment of intersectoral services in the field, with the implementation of the reference and counter, plus constant support, theoretical and psychological health professionals [12].

In order to incorporate violence against women as a demand on health services is essential to understand the development of intersectoral care practices and appropriate. What would the interplay between health and human rights (women), in search of their recovery, the restoration of ethics in interpersonal relations and integrated treatment, and political commitments that include greater gender equity and social [32,38].

The big challenge is to build an interdisciplinary approach that result in conjunction with the practices of the field of health care [37]. Therefore, the ability of the service to be in health, social care, public safety or legal, to welcome the needs of these women and have a looksolving is what determines the search for the care of women. The success of the intervention also depends on the availability, quality and coordination of services; attitudes of professionals, commitment to support women's willingness to defend their rights and ensure their safety.

Women appreciate being listened to [31,35] and value the time of consultation services in family health as a safe and confidential. Express the importance of monitoring your health and your family. It's important for her physicians to support her, on finding alternative accommodation, providing medical license and support in litigation [35]. Noteworthy is the benefit of the revelation of the situation of violence against women, who want to express and feel better after doing it. They need and want to talk about violence in private, confidential and 
non-judgmental of the fact by the professional [31].

We reiterates that, considering the complexity of the issue in question is necessary, in addition to support and care, using shares techniques such as clarification of their rights, and the coordination of services with reference centers in attendance and with NGOs support to assist women in coping with the problem [12].

\section{CONCLUSIONS}

Violence against women is a complex phenomenon, and a sociocultural order with global consequences for public health. In this sense, the challenge is cultural change in order to understand violence as something that is not natural. This requires thinking human beings, especially women, in their diversity, with the right not to suffer violence, which requires political commitment, ethical and professional with the necessary changes.

The magnitude of this phenomenon requires to reorganize health services to assist women and families in terms of their subjective needs, psychic work, access and also the biological needs, aiming at the development of an integrated care. Belief in rethinking attention in order to (re)organize the way services are structured in order to compose a network of care for women and ensuring reception of their demands is urgent. Otherwise, building skills aligned with public policies to face the problem and ensuring humane care will be fulfilled only in the field of debate as what constitutes protection limits the lives of these women and their families.

This points to the urgent need to overcome difficulties in healthcare and implement essentially nuclear training, aiming at completeness in care, being necessary to break down the barriers biomedical fragmented and move towards a multidisciplinary and interdisciplinary approach. Thus, it is understood as essential to continue education strategies as part of everyday educational institutions and service providers. Besides the necessity of thematic should be considered in the training curriculum of health professionals, and also the urgency of this learning support networking multidisciplinary and intersectoral stands out as a limitation of the study and the restriction to health. It is recommended, therefore, to develop the research covering the intersectoral approach to create links between the network of health care for women in situations of violence with social care, public safety, education, work and income, among others.

\section{REFERENCES}

[1] Costa, J.S.D. and Victora, C.G. (2006) What is a "public health problem”? Revista Brasileira de Epidemiologia, 9, 144-151. doi:10.1590/S1415-790X2006000100018

[2] Jong, L.C., Sadala, M.L.A and Tanaka, A.C.D.A. (2008) Forfeiting the denunciation of the aggressor: Reports of female victims of domestic violence. Revista da Escola de Enfermagem da USP, 42, 7441-7451. doi:10.1590/S0080-62342008000400018

[3] Brasil National Secretariat for Combating Violence against Women (2011) Secretariat of Policies for WomenPresidency of the Republic. National Policy for Combating Violence Against Women.

http://www.campanhapontofinal.com.br/download/inform ativo_03.pdf

[4] Organização dos Estados Americanos-OEA (1994) Convenção interamericana para prevenir, punir e erradicar a violência contra a mulher. http://www.direitoshumanos.usp.br/index.php/OEA

[5] Brasil Secretaria Especial de Políticas para as Mulheres (2006) Lei Maria da Penha, Lei no. 11.340, de 07 de agosto de 2006: Coíbe a violência doméstica e familiar contra a mulher.

http://www.spm.gov.br/legislacao-1/lei-maria-da-penha/le imariadapenha-1.pdf

[6] Moreira, S.N.T, Galvão, L.L.F., Melo, C.O.M. and Azevedo, G.D. (2008) Physical violence against women from the perspective of health professional. Revista de Saúde Pública, 42, 1053-1059. doi:10.1590/S0034-89102008005000058

[7] Brasil Presidency of the Republic. Secretariat of Policies for Women (2008) II national plan of policies for women. http://bvsms.saude.gov.br/bvs/publicacoes/II_PNPM.pdf

[8] Santi, L.N., Nakano, A.M.S. and Lettiere, A. (2010) Domestically abused Brazilian women's perceptions about support and received support in its social context. Texto \& Contexto-Enfermagem, 19, 417-424. doi:10.1590/S0104-07072010000300002

[9] Taquette, S.R. (2007) Teen woman in situation of violence. Publisher of the Secretariat of Policies for Women.

[10] Minayo, M.C.S. and Deslandes, S.F. (2009) Analysis of the implantation of the healthcare network for victims of accidents and violence following the guidelines of the National Policy for the Reduction of Morbidity and Mortality from Violence and Accidents. Ciência \& Saúde Coletiva, 14, 1641-1649. doi:10.1590/S1413-81232009000500002

[11] Vieira, L.B., Padoin, S.M.M. and Landerdahl, M.C. (2009) The perceptions of the health professionals at a hospital about the violence against women. Revista Gaúcha de Enfermagem, 30, 609-616. doi:10.1590/S1983-14472009000400005

[12] Leal, S.M.C., Lopes, M.J.M. and Gaspar, M.F.M. (2011) Social representations of violence against women in the nursing perspective. Interface (Botucatu), 15, 409-424. doi:10.1590/S1414-32832011005000012

[13] Rother, E.T. (2007) Systematic literature review X narrative review. Acta Paulista de Enfermagem, 20, 5-6. doi:10.1590/S0103-21002007000200001

[14] Minayo, M.C.S. (2010) The challenge of knowledge: Qualitative research in health. 12th Edition, Hucitec, São Paulo.

[15] Scaranto, C.A.A., Biazevic, M.G.H. and Michel-Crosato, E. (2007) Community health agents perception about 
domestic violence against woman. Psicologia: Ciência e Profissão, 27, 694-705.

doi:10.1590/S1414-98932007000400010

[16] Herrera, C. and Agoff, C. (2006) Dilemmas of healthcare providers towards domestic violence in Mexico. Cadernos de Saúde Pública, 22, 2349-2357. doi:10.1590/S0102-311X2006001100009

[17] Galvão, E.F. and Andrade, S.M. (2004) Violence against women: Analysis of cases attended in a women care centre in a municipality in Southern Brazil. Saúde e Sociedade, 13, 89-99.

doi:10.1590/S0104-12902004000200009

[18] Sagot, M. (2005) The critical path of women affected by family violence in Latin America: Case studies from 10 countries. Violence against Women, 11, 1292-1318. doi:10.1177/1077801205280189

[19] Leôncio, K.L., Baldo, P.L., João, V.M. and Biffi, R.G.O. (2008) Profile of victimized women and of their aggressors. Revista Enfermagem UERJ, 16, 307-312. http://www.facenf.uerj.br/v16n3/v16n3a02.pdf

[20] Hague, G. and Mullender, A. (2006) Who listens? The voices of domestic violence survivors in service provision in the United Kingdom. Violence against Women, 12, 568-587. doi:10.1177/1077801206289132

[21] Minsky-Kelly, D., Kevin Hamberger, L., Pape, D.A. and Wolff, M. (2005) We've had training, now what? Qualitative analysis of barriers to domestic violence screening and referral in a health care setting. Journal of Interpersonal Violence, 20, 1288-1309. doi:10.1177/0886260505278861

[22] Silva, I.V. (2003) Violence against woman: Clients of emergency care units in Salvador. Cadernos de Saúde Pública, 19, 263-272. doi:10.1590/S0102-311X2003000800008

[23] Kronbauer, J.F.D. and Meneghel, S.N. (2005) Profile of gender violence by intimate partners. Revista de Saúde Pública, 39, 695-701. doi:10.1590/S0034-89102005000500001

[24] Gomes, N.P., Bomfim, A.N.A., Diniz, N.M.F., Souza, S.S. and Couto, T.M. (2012) Combating violence against women: Service network personnel's perceptions. Revista Enfermagem UERJ, 20, 173-178. http://www.e-publicacoes.uerj.br/index.php/enfermagemu erj/article/view/4035/2787

[25] Stenius, V.M. and Veysey, B.M. (2005) "It's the little things". Women, trauma, and strategies for healing. Journal of Interpersonal Violence, 20, 1155-1174. doi:10.1177/0886260505278533

[26] Diniz, N.M.F., Lopes, R.L.M., Rodrigues, A.D. and Freitas, D.S. (2007) Women who were burned by their husbands or partners. Acta Paulista de Enfermagem, 20, 321-325. doi:10.1590/S0103-21002007000300013

[27] Porto, J.R.R. and Luz, A.M.H. (2004) Shades of violence against women: Understanding the phenomenon. Rev Gaúcha Enferm, 25, 207-218. http://www.lume.ufrgs.br/bitstream/handle/10183/23522/ 000504630.pdf?sequence $=1$

[28] Kim, J. and Motsei, M. (2002) "Women enjoy punishment": Attitudes and experiences of gender-based violence among PHC nurses in rural South Africa. Social Science \& Medicine, 54, 1243-1254. doi:10.1016/S0277-9536(01)00093-4

[29] Bennett, L., Riger, S., Schewe, P., Howard, A. and Wasco, S. (2004) Effectiveness of hotline, advocacy, counseling, and shelter services for victims of domestic violence. Journal of Interpersonal Violence, 19, 815-829. doi:10.1177/0886260504265687

[30] Villela, W.V., Vianna, L.A.C., Lima, L.F.P., Sala, D.C.P., Vieira, T.F., Vieira, L.M. and Oliveira, E.M. (2011) Ambiguity and contradictions in the assistance provided for women who suffer violence. Saúde e Sociedade, 20, 113123. doi:10.1590/S0104-12902011000100014

[31] Signorelli, M.C., Auad, D. and Pereira, P.P.G. (2013) Domestic violence against women and professional practices in primary health care: An ethnographic study in Matinhos, Paraná State, Brazil. Cadernos de Saúde Pública, Rio de Janeiro.

[32] D’Oliveira, A.F.P.L., Schraiber, L.B., Hanada, H. and Durand, J. (2009) Comprehensive health (care) services to women in gender violence situation: An alternative to primary health care. Ciência e Saúde Coletiva, 14, 10371050. doi:10.1590/S1413-81232009000400011

[33] Dutra, M.L., Prates, P.L., Nakamura, E. and Villela, W.V. (2013) The configuration of the social network of women living in domestic violence situations. Ciência e Saúde Coletiva, 18, 1293-1304. doi:10.1590/S1413-81232013001100014

[34] Borsoi, T.S., Brandão, E.R. and Cavalcanti, M.L.T. (2009) Actions addressing violence against women at two primary health centers in the municipality of Rio de Janeiro. Interface-Comunicação, Saúde, Educação, 13, 165-174. http://www.scielo.br/scielo.php?script=sci_arttext\&pid=S 1414-32832009000100014

[35] Narula, A., Agarwal, G. and McCarthy, L. (2012) Intimate partner violence: Patients' experiences and perceptions in family practice. Family Practice-The International Journal for Research in Primary Care, 29, 593-600. doi:10.1093/fampra/cms008

[36] Vieira, L.B., Padoin, S.M.M., Souza, I.E.O. and Paula, C.C. (2011) Perspectives for nursing care to women that report violence experiences. Escola Anna Nery, 15, 678685. doi:10.1590/S1414-81452011000400004

[37] Lamoglia, C.V.A. and Minayo, M.C.S. (2009) Marital violence, a social and public health problem: A study in a police station in the state of Rio de Janeiro. Ciência \& Saúde Coletiva, 14, 595-604. doi:10.1590/S1413-81232009000200028

[38] Schraiber, L.B., D’Oliveira, A.F.P.L., Portella, A.P. and Menicucci, E. (2009) Gender-based violence in Public Health: challenges and achievements. Ciência \& Saúde Coletiva, 14, 1019-1027. $\underline{\text { doi:10.1590/S1413-81232009000400009 }}$ 